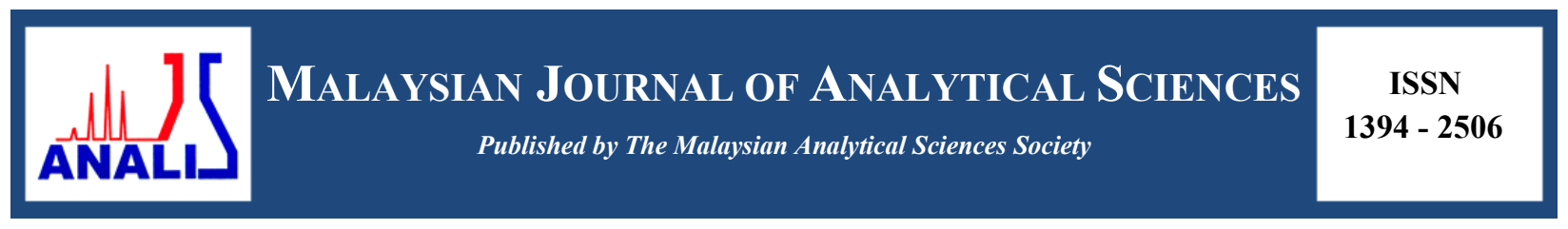

\title{
RADIOTRACER APPLICATION IN MALAYSIA: RESIDENCE TIME DISTRIBUTION STUDY
}

\author{
(Aplikasi Teknologi Penyurih di Malaysia: Kajian Taburan Masa Mastautin) \\ Noraishah Othman*, Nor Pa'iza Mohamed Hassan, Roslan Yahya, Mior Ahmad Khusaini Adnan, \\ Mohd Rabaie Shari, Hearie Hassan, Airwan Affendy Mahmood \\ Plant Assessment Technology, Industrial Technology Division \\ Malaysian Nuclear Agency, 43000 Bangi, Selangor, Malaysia \\ *Corresponding author: noraishah@nm.gov.my
}

Received: 21 October 2015; Accepted: 14 June 2016

\begin{abstract}
The residence time distribution (RTD) study at power generation plant was successfully carried out using radiotracer technology. In this study, $\mathrm{Tc}^{99 \mathrm{~m}}$ was used as the source of radioactive whereas $\mathrm{NaI}(\mathrm{Tl})$ detector was the scintillant detector. Previous study only concentrated on getting the flow rate from two successive peaks without producing any mathematical model. Thus, the hydrodynamics behaviour of the liquid inside the plant was weakly described. In this study, axial dispersed plug flow model is the best RTD model due to minimal value of sum of square which is $0.261 \times 10^{-5}$ compare to other RTD models recommended by International Atomic Energy Agency (IAEA).
\end{abstract}

Keywords: residence time distribution, radiotracer technology, RTD models, sum of square

\begin{abstract}
Kajian taburan masa mastautin (RTD) telah berjaya dilakukan di loji janakuasa elektrik menggunakan teknologi penyurih. Untuk kajian ini, Tc ${ }^{99 m}$ telah digunakan sebagai penyurih radioaktif manakala pengesan NaI digunakan sebagai pengesan sintilasi. Kajian terdahulu hanya memberi maklumat berkaitan pengukuran kadar alir yang terhasil daripada dua puncak turutan yang terhasil tanpa membuat laporan berkaitan permodelan RTD. Oleh itu, kelakuan hidrodinamik bendalir di dalam loji tidak dapat dijelaskan dengan baik. Untuk kajian ini, model aliran palam taburan aksial merupakan model terbaik RTD berbanding model yang dicadangkan oleh IAEA kerana nilai jumlah kuasa dua terhasil yang rendah iaitu $0.261 \times 10^{-5}$.
\end{abstract}

Kata kunci: taburan masa mastautin, teknologi penyurih, permodelan RTD, jumlah kuasa dua

\section{Introduction}

Radiotracers are widely used for the measurement of the flow rate of liquids, gases and solids in many industrial systems. An investigation of many major industrial applications including fluidized beds, sugar crystallizers, trickle bed reactors, cement rotary kiln, wastewater treatment unit and also inter-well communications in oil fields can be performed by the injection of a radiotracer at the inlet of the system and monitoring the radiotracer at the outlet. The output data can be treated and analyzed to investigate the behavior of the system or hydrodynamics of the fluid inside the plant. Moreover, radioisotope-based technology continues to play a rapidly growing role in assisting industry to enhance their production efficiency and also for optimization [1]. Radiotracer technology has proved itself as a sensitive tool for investigating and solving plant process problems namely process malfunctions and anomalies as well as mechanical damages. Radiotracer techniques have many advantages such as high detection 
sensitivity, in-situ detection, and availability of a wide range of compatible radiotracers for different phases, rapid response, reliability and accuracy of results [2].

The residence time distribution (RTD) of a reactor is a characteristic of the flow pattern that occurs in the chemical reactor, being one of the most informative characterizations of the reactor [3]. The principle of a tracer experiment consists of a common impulse-response method: injection of a tracer at the inlet of a system and recording the concentration-time curve at the outlet of the system. RTD is obtained after the preliminary treatment of radiotracer data, including background correction, correction, radioactive decay correction, starting point correction, filtering, and data extrapolation and area-normalization as described by Kasban et al. [4]. RTD, which was first developed by Danckwerts [5] has been utilized by many researchers to diagnose the possible system malfunctions such as bypassing, leakage, blockage, channelling, fouling and backmixing as well as helping in estimating the quality of mixing. It also depends on the flow hydrodynamics and the reactor geometry and has influence on the reactor for chemical performances such as conversion and yield. The method gives information on the measured system by evaluating concentration of a tracer compound, which is added as a stimulus at the system inlet.

Moreover, mathematical model should be obtained for hydrodynamics study so that the behaviour of the fluid in the plant or reactor can be understood well. Extensive radiotracer experiments have been carried out successfully in various industries, which indicate the survival and reliability of radiotracers in hostile environments. The next case studies will be describing the successful application of radiotracer technology in industries worldwide. Sugiharto et al. [6] determined the RTD and the system flow rate in a 24 in. multiphase flow hydrocarbon transmission pipeline containing approximately $95 \%$ water, $3 \%$ crude oil, $2 \%$ gas and negligible solid material. Nevertheless, the types of radiotracer sources used in this experiment were different; I-13 and Na-24 were used independently for the measurement of the RTD in hydrocarbons and water, respectively. In this instance, the tanks in series model best described the RTD of the system. The authors also discovered that the water moved faster than the hydrocarbon even though the density of the water is higher. This might be because water is more dominant in the transmission line and because the movement of the crude oil is slowed by friction with gas at the top layer and friction at the water-crude oil interface. Behin and Aghajari [7] studied the RTD measurement in a pilot-scale oil-water separator operated by Drood oil of the Iranian Offshore Oil Company (IOOC) located in Kharg Island using 5mCi I-131 as sodium iodide and $4 \mathrm{mCi}$ of I-131 as iodobenzene for the aqueous and organic phase, respectively. The separation of the crude oil and water mixtures is an important process in the oil and chemical industries. The researchers reported that the experimental results were in a good agreement using the model of perfect mixing tanks in series (with a dead zone) to describe the liquid behavior. The models obtained in these two case studies were both tanks in series models. It can therefore be concluded that tanks in series models suited the multiphase flow profile.

In addition, each case study developed a mathematical model that fitted the experimental results satisfactorily although the chosen models varied between applications. Pant et al. [8] conducted an RTD study in a pilot and an industrialized fluid catalytic cracking unit (FCCU) using an intrinsic tracer. The identified tracers were lanthanum140 and sodium-24 and were obtained from the catalyst sample. The tracers were characterized using neutron activation analysis to investigate the degree of axial mixing and radial distribution in the riser section of the FCCUs and to determine the residence time distribution of the catalyst. The axial dispersion model (ADM) was used to represent the actual RTD obtained from the radiotracer experiments. According to Pant et al. [8], the ADM is the best model to describe material flow in a tabular reactor, such as FCCU, because this model can describe onedimensional convection and dispersion in a pipe. Radiotracer techniques are extensively used for measurement of process parameters such as mean residence time (MRT), residence time distribution (RTD), flow rate, material inventory in full-scale industrial reactors, high detection sensitivity, physico-chemical compatibility, in-situ detection, limited memory effect and use in hostile industrial environment [1,2]. In this study, RTD was fruitfully conducted using radiotracer approach in one of the biggest Power Station in Malaysia.

Materials and Methods
About $10 \mathrm{ml}$ of eluted $\mathrm{Tc}-99 \mathrm{~m}$ from ${ }^{99} \mathrm{Mo} /{ }^{99 \mathrm{~m}} \mathrm{Tc}$ generator was engaged as radiotracer in this study. According to
IAEA 2008 [1], the injected activity of $\mathrm{Tc} \mathrm{c}^{99 \mathrm{~m}}$ is $\approx 37 \mathrm{GBq}$ is used for water tracing in surface bodies (rivers, sea) for
dispersion of effluent studies (outfalls) and dispersion coefficient measurements. Nevertheless, in this study about
10.6Bq was employed. The experiment was carried out by injection of $\mathrm{Tc}^{99 \mathrm{~m}}$ into $2.1 \mathrm{~m}$ diameter underground 
Calvert pipeline. The temperature of operating liquid is about $39-40^{\circ} \mathrm{C}$ along the $580 \mathrm{~m}$ pipeline. The injection point was chosen at the outlet of the condenser and the detection point was at the effluent of pipe which was about $580 \mathrm{~m}$ away from the injection point. This location showed that the tracer was mixing homogenously with the liquid since according to IAEA practice, the shortest perfect mixing is about 100 inner diameter length $[1,2]$. The scintillation detector, NaI was used to detect the presence of the emitted radiotracer for RTD study. Fig. 1 shows the schematic diagram of the buried pipelines. The influent and the effluents are coming from and to the sea respectively.

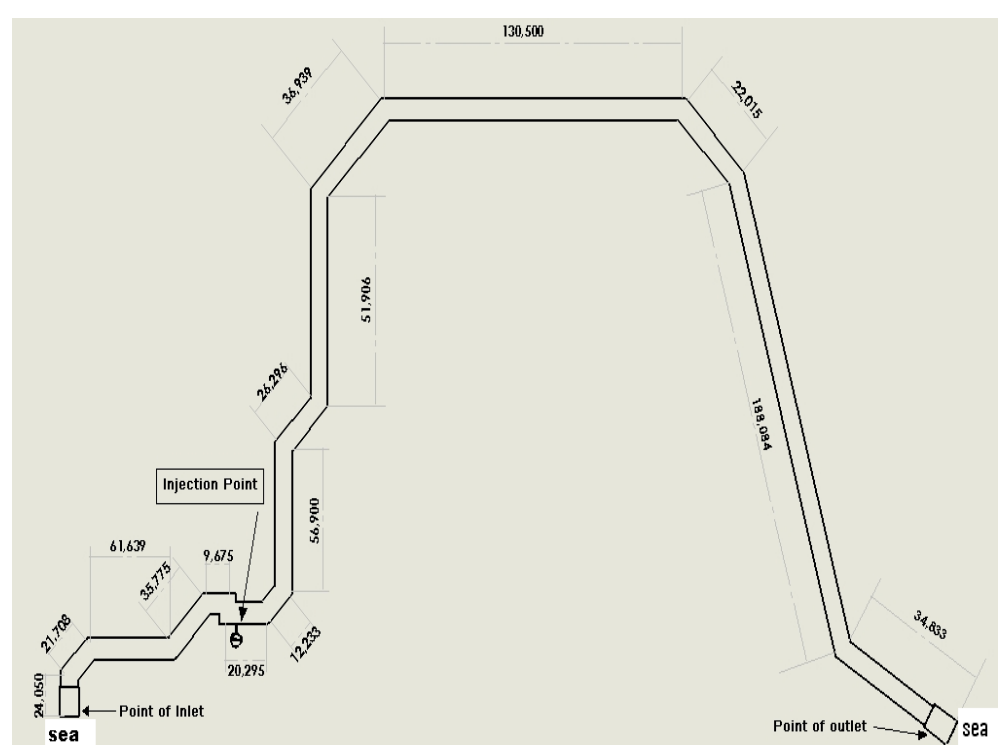

Figure 1. Schematic diagram of buried pipeline

\section{Results and Discussion}

Figure 2 shows the results of radioactive monitoring in which the gamma rays are detected in count per seconds (cps) from $\mathrm{Tc}^{99 \mathrm{~m}}$ and received by scintillation detector. The sampling time was set until the reading from data acquisition system (DAS) showed the background level. The experimental data obtained has statistical fluctuations which need to be treated prior RTD determination. The data has to undergo background correction, radioactive decay correction, starting point correction, filtration and data extrapolation prior RTD modelling.

Residence Time Distribution (RTD) is a fundamental parameter in reactor design which can give information on how long the substrate has been in the reactor and the RTD analysis can help characterizing the extent of their deviation from ideal behavior. The $\mathrm{E}(\mathrm{t})$ function is the RTD where $\mathrm{E}(\mathrm{t}) \mathrm{dt}$ is the fraction of the flow, measured at the exit, that is in the system between times $t$ and $(t+d t)$ :

$$
E(t)=\frac{C(t)}{\int_{0}^{\infty} C(t) d t}
$$

where $\mathrm{C}(\mathrm{t})$ is the concentration of radiotracer monitored by NaI scintillation detectors in counts per second (cps) as numerator and denominator is the area under the curve of plotted $\mathrm{C}(\mathrm{t})$.

Figure 3 displays the RTD response after application of Equation (1). It shows the tall, sharp and narrow peak of RTD curve or well-defined Gaussian curve which indicates homogenous mixing of radiotracer in the system. The data is continuous RTD curves which represent the relation between radiation intensity versus time. In this study, RTD modelling was performed using International Atomic Energy Agency (IAEA) RTD software. The six recommended RTD models by IAEA are the axial dispersed plug flow model, the axial dispersed plug flow with exchange model, the perfect mixers in series model, the perfect mixers in series with exchange model, the perfect mixers in parallel model and the perfect mixers with recycle model. Details of each model can be obtained from the 


\section{Noraishah et al: RADIOTRACER APPLICATION IN MALAYSIA: RESIDENCE TIME DISTRIBUTION STUDY}

IAEA $[1,2]$. Mathematical RTD models can provide theoretical information as well as the hydrodynamic behaviour of the reactor.

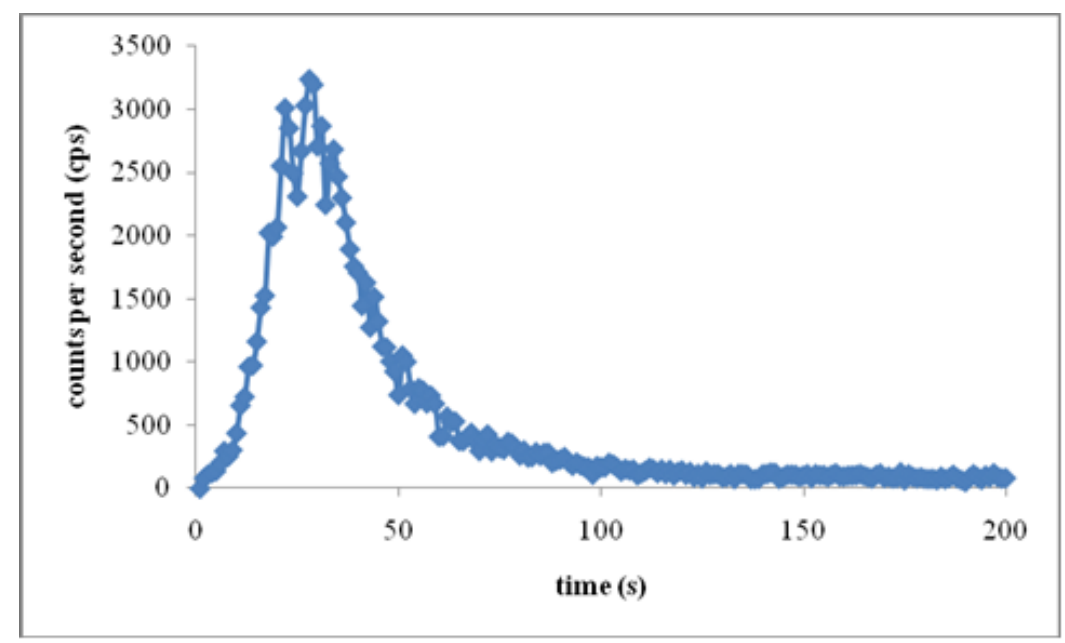

Figure 2. Detection of emitted gamma rays from $\mathrm{Tc}^{99 \mathrm{~m}}$

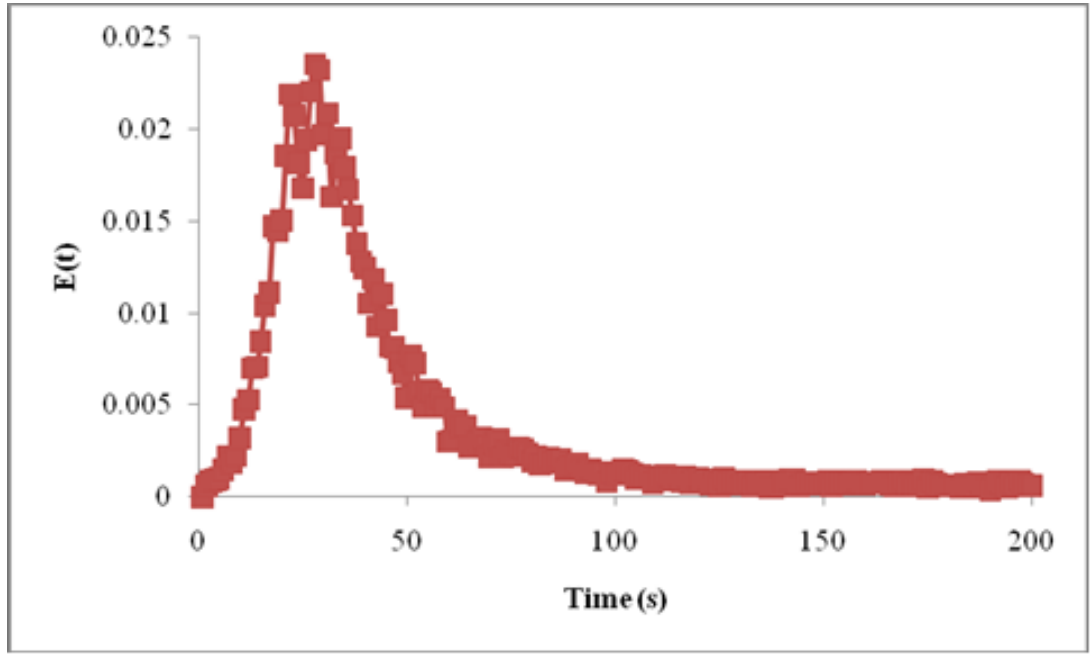

Figure 3. RTD profile of monitored tracer

The radiotracer experiments showed that only three models successfully fitted the experimental data. These RTD models are the axial dispersed plug flow model, the axial dispersed plug flow with exchange model and the perfect mixers in series model as shown in Figures 4, 5 and 6, respectively. The success of the models are due to the fact that the flow that passing through in the pipeline is behaving as plug flow which represents axial dispersion plug flow model. The unsuccessful fitted RTD model was the perfect mixers with recycle model, the perfect mixers in parallel model and the perfect mixers in series with exchange model. The failure of curve fitting from these models due to the absence of perfect mixer in the actual plant. The best fit is chosen based upon the minimum value of sum of square, which is the difference between the experimental data and the model $[1,6]$. 


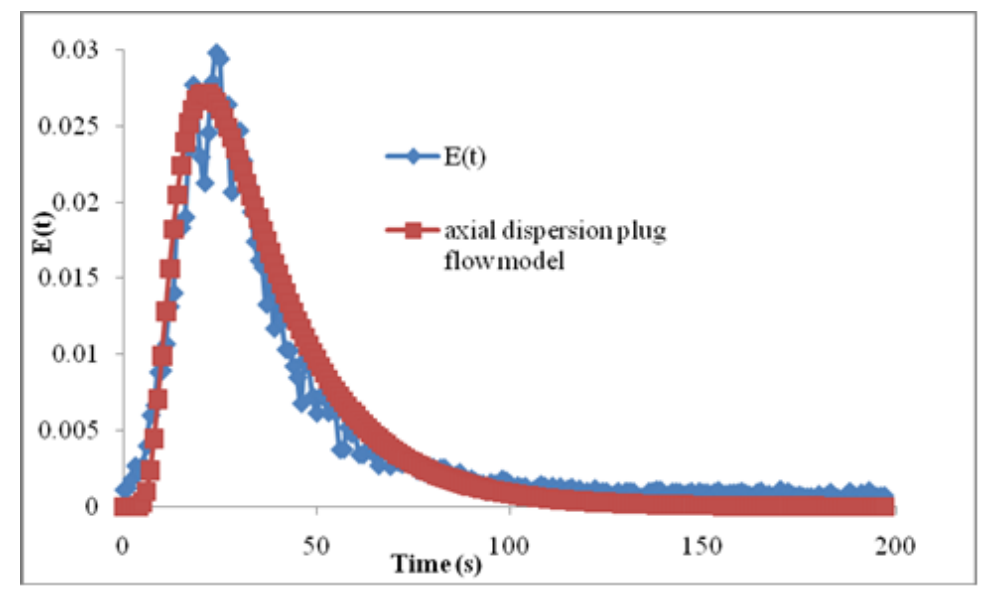

Figure 4. Axial dispersion plug flow model

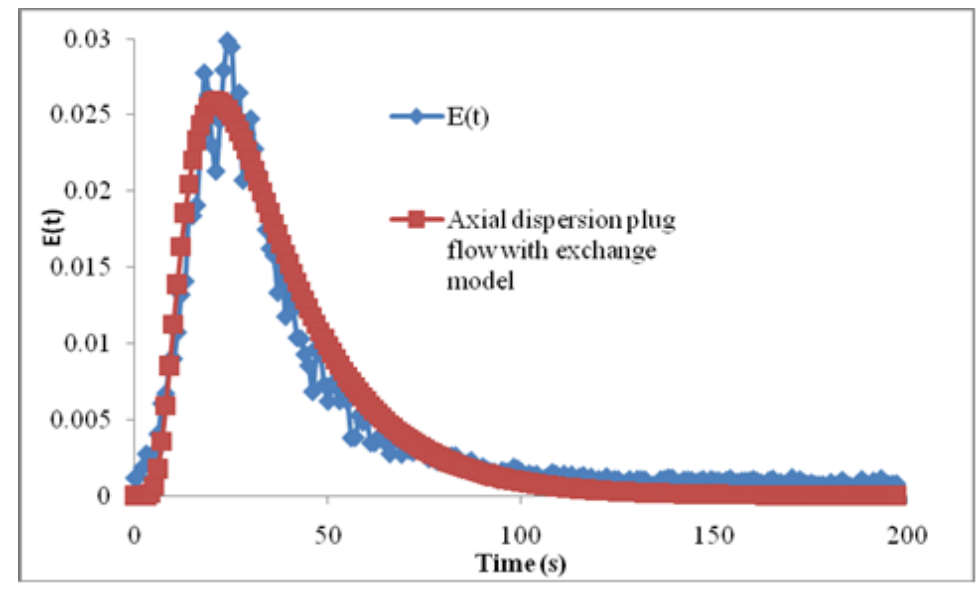

Figure 5. Axial dispersion plug flow with exchange model

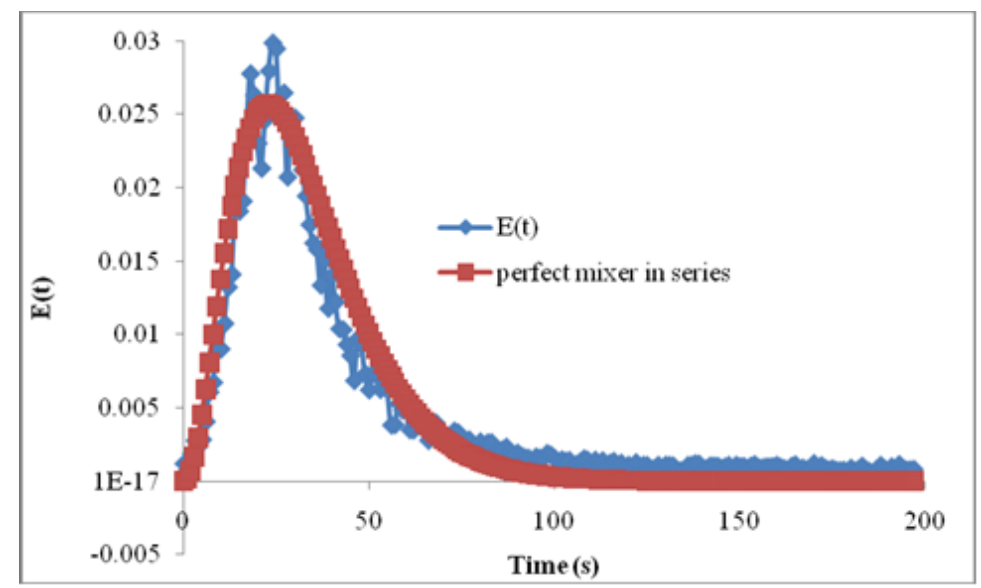

Figure 6. Perfect mixer in series model 
The axially dispersed plug flow model is widely used in practice. This flow is the superimposition of convection which is the bulk movement of the fluid as a plug and some amount of dispersion. This model is a proper approximation also for quite a variety of quasi one-dimensional situations such as river flow, underground water flow as well as packed columns and has two parameters which are non-dimensional Péclet number, Pe and $\tau$. The curves get sharper and sharper when Pe is increased. They always have one single peak and the peak height and tail length are correlated (tail is short when peak is sharp and vice versa). It is often necessary to characterize convection as related to velocities and flow rates which is the behavior of plug flow [1,2].

Furthermore, the sum of the squares of the differences between the model and the data are minimized and fulfilled using the following equation [6]:

$$
\text { Sum of Square }(S S E)=\left[\frac{1}{N_{T}} \int_{0}^{\infty}\left[E_{\text {exp }}(\theta)-E_{m}(\theta, N)\right]^{2} d \theta\right]^{1 / 2}=\text { Minimum }
$$

where $N_{T}$ is the number of data points, $E_{\text {exp }}(\theta)$ is the experimentally measured curve, and $E_{m}(\theta, N)$ is the simulated model. Table 1 shows the results of optimized parameters for successful RTD model. Only three RTD models have successfully fitted the experimental curve. These model are axial dispersed plug flow model, axial dispersed plug flow with exchange model followed by the perfect mixers in series model.

Table 1. Optimized parameters for each model

\begin{tabular}{|c|c|c|c|c|c|c|}
\hline Models & $\tau$ & $\mathrm{Pe}$ & $\mathbf{N}$ & $\mathbf{J}$ & $\begin{array}{l}\text { Sum of square } \\
\text { (SSE) }\end{array}$ & Rank \\
\hline Axial dispersion plug flow model & 0.36 & 0.53 & 1.0 & $n a$ & $0.261 \times 10^{-5}$ & 1 \\
\hline Axial dispersion plug flow with exchange model & 0.30 & 0.47 & 1.0 & 1.0 & $0.305 \times 10^{-5}$ & 2 \\
\hline Perfect mixer in series model & 0.33 & $n a$ & $n a$ & 0.33 & $0.348 \times 10^{-5}$ & 3 \\
\hline
\end{tabular}

Where $\tau$ is the mean residence time or the total volume of the system divided by the flow rate,

Pe is Péclet number,

$\mathrm{J}$ is number of tank,

$\mathrm{N}$ is a mass transfer coefficient;

$n a-$ not applicable.

According to Table 1, both the axial dispersed plug flow model and the axial dispersed plug flow with exchange model can be considered as the best fit followed by the perfect mixers in series model. The axial dispersed plug flow model is best described the experimental RTD curve because the sum of square (SSE) is minimum which is $0.261 \mathrm{x}$ $10^{-5}$ compare to perfect mixer in series, which is $0.348 \times 10^{-5}$. Additionally, the axial dispersed plug flow model is more applicable to flows in long pipes and the axial dispersed plug flow with exchange model indicates that there is effective mixing because the value of $\mathrm{N}$ is equal to $1[1,2]$. Besides, the lowest value of Pe shows that dispersion operation is more dominant than convection, and thus, there is plug flow.

\section{Conclusion}

The present work describes the radioactive experiments using radiotracer technology to study the (RTD). A field study was carried out as a case study and the best RTD models were precisely identified. The axial dispersed plug flow model, the axial dispersed plug flow with exchange model and the perfect mixers in series model are the RTD models which inflexibly fitted the experimental RTD well whereas axial dispersed plug flow model described best RTD model due to minimal value of sum of square. 


\section{Acknowledgement}

All authors acknowledge the Plant Assessment Technology team which made an outstanding effort for accomplishment of this project. They also thank the Director of BKT, NM for the financial support.

\section{References}

1. IAEA (2008). Residence time distribution method for industrial and environmental applications. Training course series 931, Vienna, Austria.

2. IAEA-TECDOC-1262 (2001). Radiotracer technology as applied to industry.Vienna, Austria.

3. Arratia, P. E., Lacombe, J. P., Shinbrot, T. and Muzzio, F. J. (2004). Segregated regions in continuous laminar stirred tank reactors. Chemical Engineering Science, 59:1481 - 1490.

4. Kasban, H., Zahran, O., Arafa, H., El-Kordy, M., Elaraby, S. M. S. and Abd El-Samie, F. E. (2010). Laboratory experiments and modeling for industrial radiotracer applications. Applied Radiation and Isotopes, 68: 1049 1056.

5. Danckwerts, P. V. (1953). Continuous flow systems and distribution of residence times. Chemical Engineering and Science, 2: $1-13$.

6. Sugiharto, S., Suud, Z., Kurniadi, R., Wibisono, W. and Abidin, Z. (2009). Radiotracer method for residence time distribution study in multiphase flow system. Applied Radiation and Isotopes, 67: $1445-1448$.

7. Behin, J. and Aghajari, M. (2008). Influence of water level on oil-water separation by residence time distribution curves investigations. Separation and Purifification Technology, 64: 48 - 55.

8. Pant, H. J., Sharma, V. K., Nair, A. G. C., Tomar, B. S., Nathaniel, T. N., Reddy, A. V. R. and Singh, G.(2009). Application of $140-\mathrm{La}$ and $24 \mathrm{Na}$ as intrinsic radiotracers for investigating catalyst dynamics in FCCUs. Applied Radiation and Isotopes, 67: 1591 - 1599. 